Rev Biomed 2002; 13:59-68.

\title{
Los recursos terapéuticos empleados en la medicina antigua de Yucatán*.
}

\author{
Historia de la Medicina
}

Carlos Urzaiz-Jiménez.

Facultad de Medicina, Universidad Autónoma de Yucatán, Mérida, Yucatán, México.

\section{RESUMEN.}

Considerar que los mayas con su desventaja evolutiva alcanzaron un grado mayor de desarrollo en el campo de la medicina, es proceder con algo de pasión. Lo que si podemos asegurar sin temor de parecer exagerados, es que la experiencia diaria puso en manos de los curanderos mayas numerosas substancias vegetales, animales y minerales de acción curativa. Pero es preciso aclarar que el uso de tales substancias no estaba reglamentado, que no se les atribuía acción definitiva ni tenían empleo especifico en determinada enfermedad. Por el contrario, se les utilizaba en forma algo irracional en la mitigación de los síntomas, cualquiera que fuese el origen de éstos, lo que de ninguna manera es inferior a lo que hacían sus contemporáneos europeos.

El ejercicio de la medicina entre los mayas quedaba encomendado a tres personajes de distinto rango, el $h$-men que era sacerdote, el $d z a-d z a c$ que era el que cura con hierbas y ha llegado hasta a nosotros con el nombre de "yerbatero" y el pul-

* Publicación póstuma. Reproducido de "Revista de la Universidad de Yucatán 1981; 23 (123):90-105. yah que es brujo o hechicero. Los mayas también se aventuraron por los campos de la cirugía ni más ni menos en igual medida que lo hicieran otros pueblos contemporáneos suyos.

Un gran interés reviste a nuestro juicio el síndrome de calor-frío entre los mayas, aunque probablemente no se trate de un concepto autóctono, sino de una aportación hecha por los conquistadores.

Todo lo expuesto hasta ahora respecto a los recursos curativos de la medicina antigua de Yucatán resalta más que nada aspectos mágicos que poco difieren de los practicados por otros pueblos primitivos; en cambio, casi nada se ha expresado acerca del manejo empírico de las plantas medicinales que, según es fama, fue muy difundido. (Rev Biomed 2002; 13:59-68)

Palabras clave: Historia de la medicina, medicina maya, medicina prehispánica.

\section{SUMMARY.}

Therapeutic resources used in ancient medicine

Solicitud de sobretiros: Revista Biomédica, Av. Itzáes No. 490 x 59, C.P. 97000, Mérida, Yucatán, México. Fax. (999) 923-61-20 Aceptado para publicación 12/Marzo/2002 


\section{Urzaiz-Jiménez.}

\section{in Yucatan.}

To consider that the mayans with their evolutionary disadvantage reached a higher degree of development in the field of medicine is to be over-zealous. What we can assure, without risk of exaggerating is that everyday experience brought several vegetable, animal and mineral substances with curing actions into the hands of the mayans. But it should be made clear that there no guidelines to follow in the use of these substances and they were not attributed as having any defnate action nor any specific use in any determined disease. Quite the opposite, they were used in an irrational way to alleviate the symptoms, irrespective of their origins, which is in no way inferior to know their european contemporaries were working.

The practice of medicine among mayans was the responsability of three people of different ranks, the $h$-men who was a priest, the $d z a$-dzac who was the one who used herbs and is nowadays known as the "quack" and the pul-yah who was the witch doctor or the medicine man. The mayans also ventured into the fields of surgery in exactly the same way as their contemporaries in other parts of the wold.

In our opinion, it is interesting to review the hot-cold syndrome among the mayans, even though we are probably not atealing with an autochthonic concept, but with a contribution from the spanish conqueors.

Until now all the research into the curative resources of the mayans has concentrated on the magical aspects which differ very little from those practiced by other primitive people; however hardly anything has been published about the empirical use of medicinal plants, which has the fame of being widely broadcast. (Rev Biomed 2002; 13:59-68)

Key words: History of medicine, mayan medicine, prehispanic medicine.

La farmacología, tal como hoy se entiende, es ciencia relativamente nueva y fue completamente ignorada por los pueblos primitivos de todo el mundo; aunque es verdad que los más adelantados desarrollaron cierto conocimiento empírico acerca de las propiedades curativas de diversas substancias, principalmente las de origen vegetal.

Las primeras tribus sedentarias y agrícolas que se instalaron en la parte norte de la península de Yucatán, datan por lo menos de mil quinientos años antes de Jesucristo, de suerte que su existencia coincide. con la de los pueblos más antiguos de Europa. Poco se sabe con certeza de sus pasos iniciales, aunque es evidente que estuvieron en inferioridad de desarrollo ya que no manejaron la rueda ni el arado y no domesticaron bestias de carga. Con todo, estos habitantes pertenecientes al pueblo maya por su origen, lograron muestras de adelanto que aun hoy causan admiración en el terreno de las matemáticas, la astronomía, la medición del tiempo, la arquitectura y un elevado concepto filosófico de la vida y hasta una aceptable organización social. También cultivaron una escritura puramente jeroglífica que por desgracia no ha sido bien descifrada. Sucesos diversos de su historia están contados de esta manera en los diferentes códices que se conservan, la mayoría de ellos en el extranjero.

Sin embargo, no todo aquel pasado grandioso permanece en la sombra. Mucho se ha llegado a saber por otras fuentes. Entre éstas, destacan los folios designados con el nombre de Chilam Balam, cada uno de los cuales completa su identidad con la mención del sitio en donde fue hallado. Estos manuscritos, obra de escritores autóctonos que aprendieron el español y la escritura latina, se expresan en lengua maya y si bien traducen costumbres arraigadas de aquella raza admirable, es prudente aceptar en algunos de ellos, cierta contaminación.

De los primeros españoles que llegaron a la península hubo especialmente entre los frailes quienes se preocuparon por esclarecer hechos pasados y entregarlos a la historia. Contamos así con información escrita en castellano, de la que es parte muy estimable la "Relación de las cosas de Yucatán", por Fray Diego de Landa (1), el religioso

\section{Revista Biomédica}




\section{Terapeútica en la medicina antigua de Yucatán.}

que en un momento de furor fanático llevó a cabo el auto de fe de Maní, uno de los pecados capitales de la conquista.

Otros importantísimos documentos son los vocabularios y diccionarios de los que se conservan algunos que han ayudado también a la investigación actual. En su conocido trabajo "Las fuentes para el estudio de la medicina nativa de Yucatán", nuestro ilustre conterráneo Dr. Don Alfredo Barrera Vásquez, hace una detallada mención de los mismos, de mucha utilidad para los estudiosos (2).

Con tales elementos a la mano no es del todo imposible reproducir un tratado erudito acerca del tema que ahora nos distrae. Desde luego no es esa mi intención. Yo sólo pretendo echar una ojeada reconocedora y superficial sobre aquellos datos, con miras de dar idea del asunto.

De antemano debo decir que si no somos capaces de retroceder en el tiempo y situarnos exactamente en la época en que los hechos sucedieron, no hallaremos en ellos nada extraordinario; pero, hay que considerar que los períodos de mayor esplendor en el pueblo maya, aquellos que se designan con los nombres de "clásico" y post-clásico", coinciden cronológicamente de manera aproximada con la Edad Media, cuando Europa, impulsada por el fervor religioso, se sumía en la penumbra y el estatismo, al menos en lo que a ciencia se refiere. En este tiempo, buena parte de los postulados hipocráticos y galénicos, los más rea1istas y valiosos, fueron olvidados. Prohibidas las autopsias, en el cuerpo humano se mantuvo en el misterio y los recursos terapéuticos se limitaron al conocimiento de unas pocas plantas tenidas por milagrosas como la zarza, la peonía, la mandrágora y otras. Las sangrías constituían el gran remedio, la panacea sin limitaciones ni contraindicación y el trabajo quirúrgico, encomendado a los barberos, tenía sus mejores manifestaciones en la sajadura de bubas y el drenaje de abscesos. Es probable sin embargo que la osteología se dejara ver en algunas maniobras menores como corrección de luxaciones e inmovilización de huesos largos fracturados. Los europeos habían salido en buena medida de la etapa de la medicina mágica, en parte por el riesgo que representaba ante la inquisición desarrollar prácticas con olor a brujería. Ya sabemos lo fácil que era entonces ser acusado por este motivo y perecer en el potro o en la hoguera. Pero los milagros y desgracias atribuidos antes a dioses buenos y malos, a deidades protectoras y endriagos malignos, se pusieron en manos de un solo Dios verdadero y un séquito de santos y santas. O sea, que de la brujería se pasó a la religiosidad. Y si al principio se buscó la salud por medio del exorcismo, apoyado en las invocaciones paganas, los sacrificios y las laceraciones de vergajo, más o menos lo mismo se intentó ahora mediante la oración y rezo, la penitencia y el cilicio y las aspersiones con agua bendita.

Considerar que los mayas con su desventaja evolutiva alcanzaron un grado mayor de desarrollo en el campo de la medicina, es proceder con algo de pasión; por ello, me desconcierta la señora Andrews de Zapata (3), cuando citando al arqueólogo Román Piña Chan, se refiere a los métodos que tuvieron para extraer alcohol y algunos venenos y asegura en consecuencia que aquellos poseyeron "conocimientos racionales y farmacéuticos muy bien fundados". Ya sabemos que este tipo de conocimientos que implican algún grado de método científico, están bien lejos del hallazgo casual y no existían por entonces en ninguno de los pueblos qué habitaban la tierra. Lo que si podemos asegurar sin temor de parecer exagerados, es que la experiencia diaria puso en manos de los curanderos mayas numerosas substancias vegetales, animales y minerales de acción curativa. Pero es preciso aclarar que el uso de tales substancias no estaba reglamentado, que no se les atribuía acción definitiva ni tenían empleo especifico en determinada enfermedad; por el contrario, se les utilizaba en forma algo irracional en la mitigación de los síntomas, cualquiera que fuese el origen de éstos, lo que de ninguna manera es inferior a lo que hacían sus contemporáneos

Vol. 13/No. 1/Enero-Marzo, 2002 


\section{Urzaiz-Jiménez.}

europeos, quienes procedían exactamente con igual criterio. En cuanto a las dosis y forma de administración tampoco había acuerdo establecido; la dosificación sólo es posible con el aislamiento de los principios activos y la medición o pesaje de los mismos, cosa que desde luego no obtuvieron. En cuanto al modo de empleo, es probable que con los extractos totales o la materia prima llegasen a preparar jarabes, infusiones, tablillas, emplastos y otras formas liquidas o sólidas y que usaran sus preparaciones tal y como ocurre hasta, hoy con algunos productos populares, tanto para aplicación externa como en uso interior.

De que ciertas prácticas eran aceptables según el saber de entonces y otras soberanas barbaridades, tenemos testimonio en las declaraciones, de Landa, de quien, transcribimos a continuación algunos párrafos.

En el capitulo XLVI relativo a las iguanas y los lagartos, el buen, obispo nos dice: "El estiércol de éstas (las lagartijas) es admirable medicina para curar, nubes de los ojos, puesto fresco en ellos". En el capitulo que dedica a las serpientes y otros animales ponzoñosos, afirma en el párrafo final: "Hay un gusanito colorado del cual se hace ungüento muy bueno, amarillo, para hinchazones y llagas, con no más de batirlos y amasarlos juntos". Al hablar de la flora los remedios recuperan alguna dignidad; así se menciona la existencia de hierbas medicinales (sin dar explicación) y luego se dice: "Hay mucha doradilla y culantrillo y una yerba con cuyas hojas cocidas y agua se quitan a maravilla las hinchazones de los pies y piernas. Hay otra muy singular para curar llagas viejas que llaman ixpalialché. Hay también otra que tiene el mismo sabor del hinojo y se come y es muy buena para cocer agua y para curar llagas". Finalmente se habla de un árbol fofo y feo aunque grande, que lleva "cierta fruta llena de tripas amarillas muy sabrosas y cosquezuelos como cañamones y muy mayores, los cuales son muy sanos para la orina".

Como puede verse basta aquí y a través de los transcrito, no es dable deducir prácticas farmacológicas avanzadas y ni siquiera adquisiciones empíricas de algún valor. Pero sería aplicar un rigor científico fuera de tono pretender juzgar tan sólo a través de estas descripciones pintorescas.

Antes que nada debemos recordar que en aquel entonces la medicina universal andaba en veremos y tenía como funciones primordiales aliviar de los síntomas, consolar en el sufrimiento y ayudar a bien morir. De las ventajas que tuvieran en este sentido la raíz de mandrágora y los rezos piadosos o las unciones con óleos sagrados sobre la caca de iguana y los aspavientos del brujo, no se ha aclarado nada todavía.

Por otra parte, aunque el obispo Landa fue gente de fiar y acucioso en sus anotaciones, es probable que no llegase a penetrar muchas intimidades que permanecen aún en secreto. Es necesario recalcar, sin que se vea en esto intención de reducir o negar las aptitudes del pueblo maya antiguo, que como todos los pueblos primitivos ellos achacaban sus enfermedades al poder oculto de los elementos, de los dioses y de los demonios y que sus sacerdotes y curanderos ejercieron básicamente la medicina mágica tal y como correspondía a. la época en que vivieron y al grado de desarrollo que alcanzaron. Muchas de las suertes que en este terreno llevaron a cabo quedan firmemente apuntadas en las observaciones de Landa, que constituyen una de las fuentes más veraces de la que han nutrido casi todos los tratadistas ulteriores. Vuelvo una vez más a este libro fundamental en busca de apoyo. En el capítulo XXVII se establecen ciertos conceptos sobre la penitencia y demás prácticas entre los mayas de entonces, que si bien no difieren mucho de otras idolatrías, revelan su modo de pensar acerca del origen de las enfermedades.

"Que los yucatanenses naturalmente conocían que hacían mal y porque creían que por el mal y pecado les venían las muertes, enfermedades y tormentos, tenían por costumbre confesarse cuando ya estaban en ellos".

"No se casaban hasta un año después de viudos por no conocer hombre o mujer en aquel

\section{Revista Biomédica}


Terapeútica en la medicina antigua de Yucatán.

tiempo; y a los que esto no guardaban tenían por poco templados y que por eso les vendría algún mal".

"Los más idólatras eran los sacerdotes, chilanes, hechiceros y médicos, chaces y nacones. El oficio de los sacerdotes era tratar y enseñar sus creencias y declarar las necesidades y los remedios, predicar y echar las fiestas, hacer sacrificios y administrar sus sacramentos. El oficio de los chilanes pueblo las respuestas de los demonios... Los hechiceros y médicos curaban con sangrías hechas en la parte donde dolía al enfermo y echaban suertes para adivinar en los oficios cosas".

Lógicamente, si se piensa así respecto al origen de las enfermedades, los recursos para combatirlas tienen que ser de la misma índole.

Otras pruebas hay en el libro de Landa que ponen en relieve las artes de brujería ya fuese con fines curativos o preventivos. En el capitulo XXXII leemos: "Para sus partos acudían a las hechiceras, las cuales les hacían creer sus mentiras y les ponían debajo de la cama un ídolo de un demonio Ixchel, que decían era la diosa de hacer criaturas". Y poco después refiere la costumbre de abstinencias y ayunos en favor de los difuntos, de quienes decían que se los había llevado el diablo, porque pensaban que de éste provenían todos los males y en especial la muerte.

El ejercicio de la medicina entre los mayas de Yucatán quedaba a cargo de un miembro de la casta sacerdotal como el ah-men, que era previamente preparado mediante un aprendizaje que incluía conocimientos generales sobre lectura, escritura, aritmética, historia, cronología aplicada al ciclo agrícola, astrología y terapéutica, naturalmente (4). Por lo visto eran más cultos que los médicos actuales. Terminado el aprendizaje recibían autorización para ejercer, en el curso de una ceremonia que se celebraba en casa de uno de los pasantes y a la cual concurrían los sacerdotes y otras personalidades. La ceremonia culminaba con plegarias e invocaciones a los dioses de la medicina.

En su "Farmacopea maya", el Dr. Don Narcizo Sousa Novelo, destacado médico y botánico yucateco, expresa que el ejercicio de la medicina entre los mayas quedaba encomendado a tres personajes de distinto rango, el $h$-men que era sacerdote, el $d z a-d z a c$ que era el que cura con hierbas y ha llegado hasta a nosotros con el nombre de "yerbatero" y el pul-yah que es brujo o hechicero. Las funciones de cada uno de ellos estaban bien definidas y aunque se supone que todos tenían capacidad para curar, sus métodos eran diferentes en lo fundamental (5).

Nos hemos ya referido bastante a los exorcismos y un poco nada más al :uso empírico de las plantas y otras substancias como recursos terapéuticos de la medicina antigua de Yucatán; pero estos medios no fueron los únicos, pues los mayas también se aventuraron por los campos de la cirugía ni más ni menos en igual medida que lo hicieran otros pueblos contemporáneos suyos. Sus conocimientos del cuerpo humano fueron parcos. La alusión que se hace de los sacrificios para justificar una especie de aprendizaje de la anatomía (4), no está cuerdamente fundada, porque estos actos no iban animados por ninguna intención de estudio y no podían desviarse de su función primordial bajo ningún pretexto. Sin embargo, hay que admitir que existen nombres mayas para designar a casi todas las vísceras del organismo, de donde se desprende que las conocieron siquiera de manera superficial. Otra cosa sería lo relativo al funcionamiento; parece que por lo menos supieron de la respiración, el pulso y la función intestinal. Fueron buenos flebotomistas y ellos mismos se sajaban las venas. Esto, que comenzó siendo un rito de penitencia, acabó en remedio curativo como en todas partes, pues Landa asienta que solían sangrar las partes afectadas con la idea de curar. También se menciona el uso de ventosas, la reparación de huesos y luxaciones y el aserramiento de los dientes con fines cosméticos (4). El kax-bak de nuestros días es el representante de los viejos maestros especializados en ortopedia.

Todo un arsenal destinado a actividades quirúrgicas ha sido rescatado en excavaciones y entierros. Si es cierto que los mayas no tenían 


\section{Urzaiz-Jiménez.}

metales que trabajar, sierras y cuchillos de diverso tamaño se adquirían en transacciones comerciales y se completaban con instrumentos de pedernal y espinas de pescado.

En su libro "Esencia del folclore de Yucatán", Don Renán Irigoyen cronista de la ciudad de Mérida, da noticia de numerosos procedimientos y recursos propios de la medicina nativa que han sido conservados por la tradición (6). Algunos de ellos están, vigentes en las poblaciones pequeñas del interior del Estado. Como todas las acciones hasta ahora mencionadas, con mezclas de brujería y empirismo. El ejercicio de la adivinación era muy popular y lo hacían los $h$-menes ayudados por un pedazo de cristal llamado zaztún. Una de las principales artes es el pedz, especie de presión digital que se realiza sobre la parte o partes afectadas al tiempo que se pronuncia en lengua maya una oración pagana como la que traducida al español a la letra dice: "Vaya el microbio del infierno al abismo. ¿Quién quita el microbio? yo quito el microbio porque tengo virtud para quitarlo. Vayan al abismo la muerte súbita, al resfriado, el dolor de costado, la lepra, la disnea, la retención de orina. ¡Vayan al abismo!".

Tan común y afamado como el pedz es el cocán el cual se aplica con rezos y ceremonial adecuados. Consiste en utilizar unos dientes de culebra a modo de estiletes para punzar las venas y hacer sangrías. Los dientes de culebra pueden ser reemplazados por púas de puerco-espín o por alguna espina fuerte de origen vegetal. Igualmente curiosas son otras medidas por demás ingenuas empleadas para bajar la fiebre y mitigar otros síntomas; una de ellas, la mas sencilla de todas, consiste en darle nueve vueltas a una alpargata y dejarla boca. abajo en el suelo y una más que es fácil de realizar y se dice muy efectiva, pero que no deja de tener riesgos, es poner un pollo o una gallina en la cabeza del enfermo y al influjo de un ensalmo, "pasa la enfermedad al animal".

Entre las aplicaciones de las plantas hay formas que han llegado casi intactas a nuestros días; tal es la costumbre del baño con hierbas o con hojas, que tenía como fin alejar a los malos espíritus. Si no con la misma intención, hace unos cuarenta años muchas parturientas de la ciudad de Mérida solían bañarse a lo ocho días del alumbramiento con agua en la que se maceraban hojas de naranja o de guayaba.

Un gran interés reviste a nuestro Juicio el síndrome de calor-frío que ha despertado a últimas fechas el entusiasmo de los investigadores y que de acuerdo con los doctores John y Christine McCullough "constituye un flexible grupo de ideas relativas al estado termal y al equilibrio de la naturaleza con énfasis especial en los seres humanos y en los factores que más les conciernen" (7). Según dichos autores este concepto es conocido en diversas áreas tropicales y subtropicales al parecer con distintos antecedentes culturales y biológicos. Por tanto, no es exclusivo de Yucatán.

Aun cuando las referencias actuales acerca de este síndrome enfocan sobre todo a la clase de alimentos y a la nutrición del yucateco de hoy y han sido obtenidas con visión más antropológica que médica, deben llamar nuestra atención y echar luz sobre aspectos no estudiados de la medicina vernácula. Los conceptos de frío y de calor de carácter termométrico son ajenos a la calidad intrínseca de calor o frío que puede formar parte del individuo, de su naturaleza o del ambiente que le rodea y las cosas que come o usa. Según esto, una persona caliente tendrá en su interior un punto de referencia caliente, la mano y la sangre calientes también. Un individuo frío tiene idénticos puntos fríos. Hay además personas intermedias que son más o menos calientes o frías. Es decir, tibias.

Como antes dijimos, comida, objetos y elementos ambientales, tienen también su condición temperamental y afectan al organismo de acuerdo con esta peculiaridad. Es apenas probable que las enfermedades entre los antiguos mayas fueran sujetas a semejante clasificación; pero de serlo, estaríamos seguros aún en nuestros días, que sus medicinas se aplicarían contrapuestas a la calidad termal fría o caliente del padecimiento. Pongamos

\section{Revista Biomédica}


Terapeútica en la medicina antigua de Yucatán.

de ejemplo al romero que en el "Libro del Judío" se cita con carácter caliente, seco y sudorífico y se recomienda para evitar frialdades.

Los McCullough presuponen que el síndrome de calor-frío se basa en hechos científicos y está relacionado con el equilibrio ácido-base. Esto es difícil de creer aun suponiendo que el concepto expresado fuera uno de los muchos fenómenos biológicos descubiertos en el terreno de los hechos con ayuda de la casualidad y el empirismo.

De los autores mencionados transcribo integro un párrafo que me ha parecido sugestivo:

"Además, si el síndrome está basado en el metabolismo electrolítico, el médico yucateco sî podría usar tal conocimiento en su diagnosis de las enfermedades, en la historia del paciente y en la explicación de métodos curativos a los pacientes rurales quienes son ahora los menos receptivos a las curaciones médicas científicas y los más conocedores del síndrome. Este vacío entre medicina científica y creencia popular, posiblemente se puede colmar a satisfacción de ambos, paciente y médico. De aquí que nuestros resultados sean de interés tanto para la antropología médica y aplicada, como para el médico yucateco rural".

Por si alguien se ve en la necesidad de apelar a ella con fines curativos o dietéticos, he aquí una lista de alimentos, ocho calientes y quince fríos, sacados de la misma fuente informativa; entre los primeros tenemos: carne, hígado de res, huevo entero, almendra, chuleta de cerdo, cacahuate tostado, pavo y vino; como puede estimarse los más de ellos son propios de una cena de Navidad y están fuera del alcance de nuestros aborígenes pasados, presentes y futuros; entre los alimentos fríos figuran: plátano, camote, limón, naranja dulce, leche de vaca, clara de huevo, jitomate, higo, piña, durazno, sandía, chile dulce, lechuga, frijol y pan, los que desde luego resultan más accesibles; aunque algunos no satisfarían el gusto de los supuestos consumidores.

Cabe hacer notar, cosa que también señalan los McCullough, que el síndrome de calor-frío no deja de tener relación con la teoría hipocrática de los humores y que los griegos atribuyeron cualidades termales a sus remedios terapéuticos. Por lo que probablemente no se trate de un concepto autóctono sino de una aportación hecha por los conquistadores.

Todo lo expuesto hasta ahora respecto a los recursos curativos de la medicina antigua de Yucatán resalta más que nada aspectos mágicos que poco difieren de los practicados por otros pueblos primitivos; en cambio, casi nada se ha expresado acerca del manejo empírico de las plantas medicinales que, según es fama, fue muy difundido. Así parece demostrarlo la tradición y en épocas recientes, el conocimiento se ha enriquecido con lo qué añadieron a esa tradición los estudiosos del tema, entre los que cabe mencionar a muy reconocidos botánicos yucatecos cómo los señores Joaquín y Juan Dondé, padre e hijo, que hicieron estimable esfuerzo en este sentido a fines del siglo pasado; el Dr. Benjamín Cuevas, contemporáneo de los anteriores y cuyo libro "Plantas medicinales de Yucatán y guía médica práctica doméstica" vio la luz en 1919 (8); el Dr. Geo F., Gaumer, norteamericano que residió en: Izamal; el Dr. Román Sabas Flores, originario de Campeche, que escribió y publicó múltiples artículos al respecto; el licenciado en farmacia Don Enrique Escalante Solís que patentó diferentes preparaciones vegetales; el Dr. Gaspar Lavadores, maestro de la Escuela de Medicina en varias materias y autor también de un libro sobre el mismo asunto (9); el Dr. Alejandro Cervera Andrade que investigó las propiedades curativas del maíz y su uso entre los aborígenes y el Dr. Narciso Sousa Novelo que consagró su vida a estudios de esta clase y que amén de ensayos y escritos diversos, algunos de ellos inéditos, es autor del interesante folleto "Farmacopea maya" que ya he mencionado antes y de otro titulado "Plantas medicinales que viven en Yucatán" (10).

Prolija sería la relación de todas las plantas estudiadas a través de estos señores y sus tratados, por lo que remito a quienes se interesen, a las 


\section{Urzaiz-Jiménez.}

fuentes de origen, la mayoría de las cuales puede ser localizada. Pero sí quiero antes de terminar hacer mención del vehículo de enlace, el medio que perpetuó los rudimentarios estudios primitivos y dio pábulo a los actuales. Me refiero a los antiguos manuscritos que genéricamente han recibido el nombre de "Libro del Judío". Digo que genéricamente porque tales manuscritos son varios que andan dispersos por el mundo sin que se sepa. exactamente cuál es el original, pero que se parecen bastante los unos a los otros al grado de que no dejan duda de que constituyen una cadena de copias con omisiones y adiciones de mayor o menor importancia. Son en lo básico recetarios populares que nada tienen de científicos y ni siquiera se limitan al descubrimiento casual y al empirismo sino que se mezclan en gran medida con la brujería y la magia. Anónimos y de obscuro origen, pretenden ser legado ancestral de la medicina indígena. No obstante, los conocedores, del asunto atribuyen el primero de estos recetarios a la pluma de un médico venido de Roma y radicado en Valladolid a principios del siglo XVIII, llamado él Giovani Francesco Mayoli. Conocido el tal señor con el sobrenombre de El Judío, deriva de allá la designación que siempre se ha hecho de los manuscritos mencionados, los que por otra parte se ostentan facsímiles del legendario original. Así pues, por "Libro del Judío" habremos de tomar cualquiera de los ejemplares por allá desperdigados.

De lo que haya de cierto en esta leyenda, nada se puede afirmar. Investigadores como el Dr. Don Alfredo Barrera Vásquez que es autoridad en la materia, aseguran que si bien hubo un primer escrito atribuible al médico romano Mayoli el cual firmó con el seudónimo de Ricardo Ossado, todos los demás son reproducciones parciales e incompletas, entremezcladas y que poco tienen que ver con el original, especialmente las escritas en parte o en su totalidad en maya, lengua que el médico italiano no llegó a dominar (2).

Como quiera que fuese muy recientemente salió a la luz una edición impresa del citado libro, editado por la Sra. Dorothy Andrews de Zapata; quien a más de comentarios de su cosecha, reproduce las advertencias halladas en las primeras páginas del manuscrito y mantiene los giros de lenguaje y modismos que adornan el ejemplar que tuvo o que tiene a su disposición (3).

Largo y con dejo de cosa añeja, reza el título: "El libro del Judío o Medicina Doméstica. Descripción de las virtudes de las yerbas medicinales de Yucatán", por el Dr. Ricardo Ossado, 1834. A continuación se reproduce en forma que supongo alterada, un encabezado o prologuillo que es como sigue: "Descripción de los nombres y virtudes de las yerbas indígenas de Yucatán y las enfermedades a que se aplican. Copia fiel tomada del original manuscrito que dejó el famoso médico romano Don Ricardo Ossado (a) El Judío, que vivió en el pueblo de Valladolid en el siglo XVIII, encontrado en el archivo particular de Doña Petrona Carrillo viuda de Valladares, del pueblo de Ticul. Giovani Francesco Mayoli fue el verdadero nombre con que se le conoció en Valladolid a este famoso botánico, quien falleció en esta población el 27 de mayo de 1770. Por sus prodigios en la medicina doméstica, la plege ignorante que al fin se le quedó (sic) no por ser enemigo de la religión católica, sino porque el vulgo de aquella época así llamaba a los forasteros que llegaban a Yucatán y que entonces eran muy raros. Mérida de Yucatán. En la oficina del copiador, año de 1834. Copia fiel hecha por Don Feliciano Buenfil dedicada a los pueblos que carecen de facultativo".

Hay en estas líneas descriptivas una parrafada añadida atribuible sin duda a la editora que, en su afán de esclarecer el contenido, lo obscurece más.

Viene luego en el contexto de las páginas subsiguientes una serie de nominaciones de plantas y relación de recetas carentes de sentido común. No cabria esperar otra cosa toda vez que aún escrito por el auténtico médico Mayoli, cosa que es de dudar, no le faltarían barbaridades si lo juzgamos a las luces del conocimiento actual. El propio Don Francesco, según la pequeña biografía que del señor tuve a la mano (11), fue un poco

\section{Revista Biomédica}


Terapeútica en la medicina antigua de Yucatán.

raro en sus artes, algo heterodoxo en su modo de curar y pitoniso o visionario al estilo de los viejos aedas a la hora de establecer pronóstico; aunque asegura, eso sí, que era muy acertado en sus tratamientos. En los manuscritos en cuestión, por lo menos en los que están disponibles, se sospecha la intromisión de manos ajenas. Y es de creer que muchas de las añadiduras han venido del vulgo. De allá que los recetarios resulten a veces disparatados y risibles. Es de hacerse notar que algunas de las plantas que se mencionan tienen fama de curativas en el presente y se emplean todavía en las poblaciones del interior del Estado y eran de uso común en la ciudad de Mérida hasta hace no mucho tiempo. De las que relaciona el manuscrito, a veces se hace somera descripción macroscópica que ayuda a identificarlas; a las más se les cita por su nombre: popular y no se les sujeta a ninguna clasificación.

He aquí unas cuantas entre las más prestigiadas y conocidas en nuestros días:

La altaniza (artemisa) es como un filtro de amor, da ánimo, quita el cansancio y corrige las reglas de las mujeres; la corteza del. pochote cura erupciones y granos; el toronjil y la manzanilla son estomacales, el cocimiento de nabo cura la tosferina; la claudiosa tiene hojas que molidas en sebo de res y aplicadas en untos, cura hinchazones de vientre y sirve entre otras cosas para lavados vaginales; pakal o naranja agria, su jugo mezclado con sal se aplica sobre la parte afectada en golpes y magulladuras y evita postemas y tumores internos; en el recetario del Judío se recomiendan las hojas del chile habanero en infusión para los flujos de sangre que padecen las mujeres; pero en el creer del vulgo, el fruto masticado e ingerido cura las almorranas; la infusión de hojas de balché cura las fiebres tercianas y cuartanas y sirve también para preparar una bebida embriagante; la infusión de corteza de chucum alivia la picadura de animales ponzoñosos; el chile max también es recomendado en las almorranas; el pepino cat es diurético; el kutz o tabaco tiene múltiples aplicaciones; el xcanlol es una verdadera panacea: cura el asma, arranca la flema, cura el derrame de bilis, los males del hígado y del vaso (sic), alegra el corazón, da apetencia, es eficaz para los dolores de cabeza, oídos, muelas, mal olor de boca, el mal de ojos, aclara la vista, destruye las cataratas, da buen color al rostro, favorece la orina, disuelve la piedra y hace expulsar los cálculos, es contra la mordedura de víboras y cura la diabetes; el xtabentún es diurético y sirve para preparar un licor exquisito; el xtocabán tiene varias acciones pero destaca la antidiarreica cuando se le aplica en lavativas; el elemuy es diurético, la ruda abortivo, el xput-balam bueno para los males de la garganta, el llantén vermífugo y amebicida. Lugar aparte merece la závila de la cual se dice lo siguiente: "Hay de dos clases, la del monte y la de los poblados, pero las dos tienen las mismas propiedades curativas. Es fresca y suave para curar calenturas con el cocimiento de sus hojas. La babosidad se a las gallinas que tienen moquillo, mezclada con un poco de sebo de res y sana rápidamente. También es buen fortificante del cuero cabelludo lavándose la cabeza con agua fresca mezclada con rebanadas de sus hojas".

Lo impresionante es que a últimas fechas la závila ha recuperado en grande su antiguo prestigio y es muy estimada por sus propiedades regeneradoras del cabello, lo que pone de relieve el optimismo y la buena fe de los calvos.

Mucha y muy curiosas son en fin las recomendaciones que se hacen en el Libro del Judío sobre el uso de las plantas de la región. En total, entre remedios de propiedades varias y recetas específicas contra determinados males, el libro trae 526 pequeños apartados.

En está relación muy incompleta sólo he querido dar noticia de las plantas más usadas; pero no debo pasar por alto algunos de los males específicos que se pretende curar de acuerdo a ciertas recomendaciones; ello nos dará una idea de la patología mejor conocida en el medio y que mayor preocupación causó. En el manuscrito hay complejas recetas contra tuberculosis pulmonar, lepra, epilepsia, reumatismo, paludismo, dolor de corazón (?), desmayos, catarros comunes, 


\section{Urzaiz-Jiménez.}

inapetencia, aire maligno, sirro (?), mal de piedra, cálculos y arenillas, lobanillos, asma, hidropesia, llagas de la boca, escorbuto, úlceras internas, baile de San Vito, hemorroides, incordios y fístulas, mal gálico, calvicie, impotencia y una muy curiosa que se dice capaz de curar a maridos engañados y ofendidos.

Como puede apreciarse en estas notas finales, el Libro del Judío abarca los campos más insólitos de la patología orgánica y funcional, e invade el territorio de lo social dada la frecuencia de algunos de los males que combaten sus recetas, especialmente los tres que se nombraron en último término, el recetarlo no debería faltar en ningún rincón del mundo con médico o sin el.

Al llegar al término de esta revisión apoyado en mi escasa experiencia personal y la bibliografía que tuve a la mano, quedo convencido de que los recursos curativos en la medicina antigua de Yucatán fueron innumerables y variados; pero alguna duda me dejan acerca de su eficacia y no creo que hayan aportado gran cosa a la medicina moderna; influyeron, sí, antes de ser arrollados por el poderío de la industria farmacéutica sobre los médicos que ejercieron en la península en tiempos pasados y que desarrollaron una experiencia muy respetable. Aún hoy es posible encontrar en poblados del interior, representantes y defensores de este empirismo. Y sería injusto pasar por alto sus virtudes, pues los remedios que emplean son baratos, inocuos y muy útiles en los padecimientos psicosomáticos que suelen ser los más frecuentes en todos los grupos humanos y en todas las épocas. Cabe decir entonces que la "farmacopea maya" en cierta forma llenó su cometido. Además, fuera de los 25 ó 30 medicamentos específicos y realmente eficientes con que cuenta la farmacopea moderna, todos los demás, tantos tal vez como los refiere el Judío en su libro, están en el mismo predicamento que aquellos; con la desventaja de que siendo muy activos son más peligrosos y que necesariamente son mucho más caros.

\section{REFERENCIAS.}

1.- de Landa Diego. Relación de las cosas de Yucatán. México: Editorial Porrua S.A.; 1959.

2.- Barrera-Vásquez A. Las fuentes para el estudio de la medicina nativa de Yucatán. Rev Biomed 1999; 10:25361.

3.- El libro del Judío Aumentado con fuentes de información por la Dra. Dorothy Andrews Heath de Zapata. Mérida: Edición de la Dra. Dorothy Andrews. 1979.

4.- Guerra F. Maya Medicine. Medical History. VII: i; 1964.

5.- Souza-Novelo N. Farmacopea maya. Mérida: Edición del Instituto Agrícola Técnico Henequenero; 1940.

6.- Irigoyen R. Esencia del folklore de Yucatán. Mérida: Ediciones Gotero; 1968.

7.- McCullough JM, Christine S. Las creencias del síndrome de calor-frío en Yucatán y su importancia para la antropología aplicada. Anales de Antropología. (México) 1974; vol. 11.

8.- Cuevas B. Plantas medicinales de Yucatán y guía médica práctica doméstica. Mérida: Imprenta de la Lotería del Estado; 1919.

9.- Lavadores G. Las 119 plantas medicinales más conocidas en Yucatán, México. Mérida: Edición del autor. 1969.

10.- Souza-Novelo N. Plantas medicinales que viven en Yucatán. Publicación del Instituto Técnico Agrícola Henequenero. México: Dirección General de Agricultura; 1946.

11.- Diccionario Universal de Historia y de Geografía. Mayoli (signore Giovani Francesco). México, D.F. 1854.

\section{Revista Biomédica}

